\title{
IoT Based Solar Power Management Using Smart Switching
}

\author{
D. Selvabharathi, Tamanna Bhatia, Daksh Sharma
}

\begin{abstract}
A small scale sun based power the board engineering for self-controlled Internet-of-Things hub is exhibited in this paper. So as to conquer the human blunders, physical work and cost diminishing in vitality utilization with more effectiveness for the power the executives' framework, in this paper, we center for the most part on IoT's vitality checking. The proposed structure is to execute an exceptionally easy remote sensor system and convention for savvy vitality and web application prepared to do consequently perusing the component and forwarding information naturally for the control clients see their present vitality measure per use. Utilizing the framework, clients can know about the power use in their house to diminish the power consumption and price of utilization. This framework comprises the computerized vitality measure, ESP8266 Wi-Fi modem as well as the web requests for the board framework. ESP8266 Wi-Fi module is inserted in the system and execute the TCP/IP convention for the correspondences within the system. The trial output demonstrates that suggested framework runs great with proficiency, and is plausible to execute in viable uses for extremely minimal effort fabricate programmed vitality meter perusing.
\end{abstract}

Keywords-Renewable Energy, Internet of Things, solar energy, Wi-Fi.

\section{INTRODUCTION}

The utility of individual sun based board observing gadgets was investigated after the Fukushima-Daiichi atomic mishaps in Japan. The original observing gadgets were outfitted with sensors for checking voltage, current and temperature. Ethernet availability for these gadgets were additionally created. The second era SMDs had improved hardware, radios for Wi-Fi network, transfers and another variety of sensors. The third era gadgets around then appeared to be extremely goal-oriented plane to regard sun powered boards as Internet-of-Things (IoT) hubs.

The quick progressions in web advancements, another ramification of period of pervasiveness is figured out. A huge increase in users of the Internet and changes of web connected with development empowers organizations management of consistent items. It's regarding the real thing interacting with one another, machine to machine

correspondence and individual to machine interchanges are stretched into "things". The major advances that inspire the future of IoT will correspond to Smart device advances including WSN, Nanotechnology and Miniaturization. From when the introduction of earth, practically every single animal on the planet can't make due without the light and warmth conveyed by the sun. In times past, people did not progressively consider how to utilize sunlight based vitality better, simply utilizing sun oriented vitality latent. In the circumstance of debilitating petroleum derivatives, individuals start to focus on the unending sun oriented vitality. As per records, human utilized sun oriented vitality as power and vitality since a long time ago. Nowadays individuals bit by bit have confidence in the sun based vitality is "the reason for future vitality structure" and" The ongoing much needed additional vitality". Presently, sunlight based vitality has turned into an indispensable vitality that can be used by human and suffer to be created. Sun oriented vitality is generally alluded to brilliant vitality of daylight.

Sun based power plants should be checked for ideal power yield. This recovers proficient power yield from power plants by observing for broken sun based boards, associations and residue aggregated on boards bringing down yield and different issues influencing sunlight based execution. So here we propose a computerized IoT based sun oriented power checking framework that considers mechanized sunlight based power observing from anyplace over the web. We use PIC microcontroller based framework to screen sunlight based board parameters. Our framework always screens the sun based board and transmits the power yield to IoT framework over the web. The IoT shows these parameters to a client utilizing a compelling GUI and furthermore cautions client when the yield falls underneath explicit points of confinement. This makes remotely observing of sunlight based plants simple and guarantees best power yield.

\section{METHODOLOGY}

In the proposed system we are using the PIC microcontroller for the efficient monitoring of solar power management system. The voltage and current sensor are used to measure the current and voltage levels in solar system. Smart Switch is used to switch between Solar and DC power supplies. All the unit used and is calculated in the EB section. All the information is displayed in the LCD. And this information is updated to the IoT(cloud). GSM module sends

Tamanna Bhatia, Department of Electrical and Electronics Engineering, SRM Institute of Science And Technology, Kattankulathur, Chennai, Tamilnadu, India.(Email: tamannab35@gmail.com)

Daksh Sharma, Department of Electrical and Electronics Engineering, SRM Institute of Science And Technology, Kattankulathur, Chennai, Tamilnadu, India.(Email: daksh5624@gmail.com) 


\section{IOT BASED SOLAR POWER MANAGEMENT USING SMART SWITCHING}

one notification to the user on the mobile.

\section{SYSTEM ANALYSIS}

A Remote observing framework for sunlight based power source face four primary difficulties; average time to fix is dreary, resoluteness, reduced reasonability, trouble in keeping up. The proposed framework has an incredible adaptability by utilizing GPRS innovation to interconnect the sunlight based capacity to Remote changes to perform wanted exchanging. This will diminish the upkeep cost and will build the proficiency of the framework. We have defined two modes of operation:

a) Solar Power mode :

In this mode the received irradiance is greater than threshold amount that is received power is greater than the required power (threshold power) so the monitoring device will switch to solar power source. In this way the self-monitoring

System is independent from the main system. And any faulty situation can be efficiently be monitored regardless of the fault. In the below figure medical device monitoring heart rate, body temperature is is solar powered even in the case of power cut.

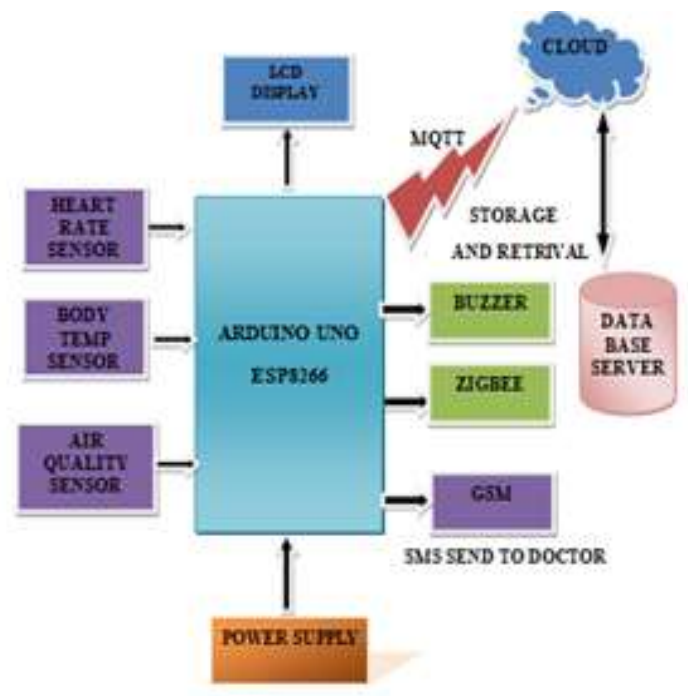

Fig. 1: Solar power mode/ battery powered. (a) if irradiance is sufficient power supply is solar.(b)if irradiance is insufficient then it is battery powered.

b) Battery/main power line mode:

In this mode the received irradiance is less than threshold amount that is received power is less than the required power (threshold power) so the monitoring device will switch to battery power source or to main power line in some cases. In this way the self-monitoring System bypasses the faulty situation and remains unaffected.

\section{SYSTEM MODELLING}

To accomplish the objective of building up a brilliant self-checking framework that is equipped for screen in any serious condition, we pursued the accompanying technique:

1. Thorough study of the existing problem

2. Select appropriate components for optimum performance.
3. Simulating the hardware circuit after sensor integration 4. Integration and Assembly of whole system

\section{Architecture}

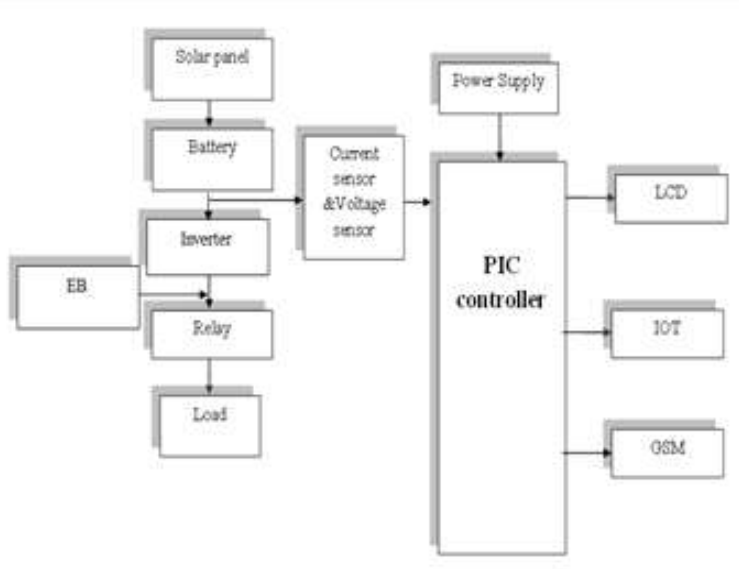

Fig. 2: Block diagram representation

\section{B. System Design and Implementation}

The design of a proposed observing arrangement of sun powered controlled checking gadget is as appeared in the figure.2. The Proposed framework basically comprises of two squares implanted framework entryway and host organize. In the suggested framework, Host organize and implanted framework passage shapes a centre of IoT framework. In the main organization we utilized a GPRS modem (NODEMCU) to interface Solar photovoltaic PCU to the web. In inserted framework entryway we utilized PIC Microcontroller modem which is utilized to interconnect the sun based power source to the GPRS modem. At first the Embedded framework portal starts the association of GPRS modem. At the point when the association is set up installed framework door will begin accepting the parameters from sun powered power source utilizing sequential correspondence UART port. The information from the sunlight based power source is gathered in the inserted framework door and exchanged to GPRS modem utilizing sequential UART port and nearby LCD show. The GPRS modem will have the gotten information in approved IP address of site through web. The information gathered from the sensors received by the internet server and put away in the cloud. The data can be scrutinized anyplace anytime. The approved individual can screen every one of the parameters through the web by means of internet server.

\section{C) Software Design}

On web page we utilized HTML (Hyper Text Mark-up Language) for the design in the front end. It is an organization that tells a PC to show a site page. The records themselves are plain content documents with unique "labels" that are used by the internet browser to translate and show data at the PC screen. It is also a content document having little increase labels. The increase labels advise the online program as to show the webpage. A HTML record must have an htm or html document augmentation. At that point we utilized CSS 
for characterizing the textual style family, textual style intensity, text dimension and the pattern of the content on site page. We executed a bootstrap responsive structure for changing the design, magnitude and dimensions of the page as indicated by the client end gadget like portable, tablet and workstation. We used jQuery for a module like pattern and data selector in website page. In site page, we utilized Ajax for refreshing a site page without the page being reloaded. The site page is planned as unique, intelligent page with the assistance of PHP (Hypertext pre-preparing) the language scripted on the side of the server. The act of using random servers on the web to oversee, stock and procedure information as opposed to utilizing a PC is distributed computing. Distributed computing is the centre of Internet of thing. In the suggested structure we actualized the distributed computing idea by utilizing PHP, MySQL and JavaScript for retrieving information, putting away in information base or controlling put away information. Here we are putting away the information in MySQL database that keeps running in Apache server. The information put away in record is controlled utilizing JavaScript.

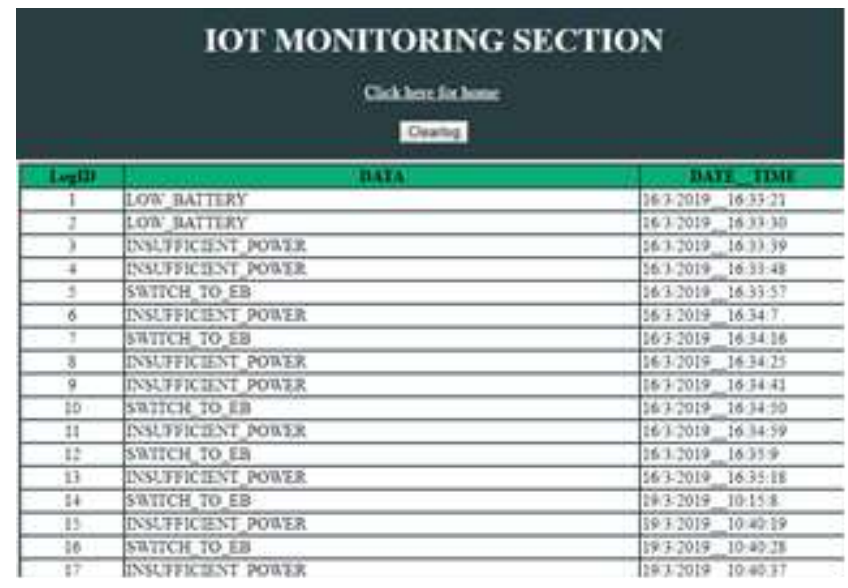

Fig 3: IoT monitoring section.

\section{D) Implementation Setup}

At the point when the information got from sensors the association among GPRS and Embedded framework door are instated. In the wake of instating GPRS now the implanted framework entryway gathers the information from sensors and put away in impermanent cradles. In installed framework entryway we utilized $\mathrm{C}++$ for arranging PIC Microcontroller. At the point when all the parameter got from the sensors, at that point implanted framework door begins to transfer information to a GPRS modem and a GSM module sequentially. Presently the GPRS Modem is going to have the information in random server in determined time interim. Hence the GPRS module has facilitated every constraint of site page through web. In website page got information are stored in MySQL databank which in turn facilitates the apache server assisting the language scripted on the side of the server. At that point the put away information of the database is handled and controlled with assistance of Java scripting. Long last the constraints is shown in a client end site page. Information got from embedded framework entryway is send as a message to the client with the assistance of GSM module.

\section{E) Simulation Results}

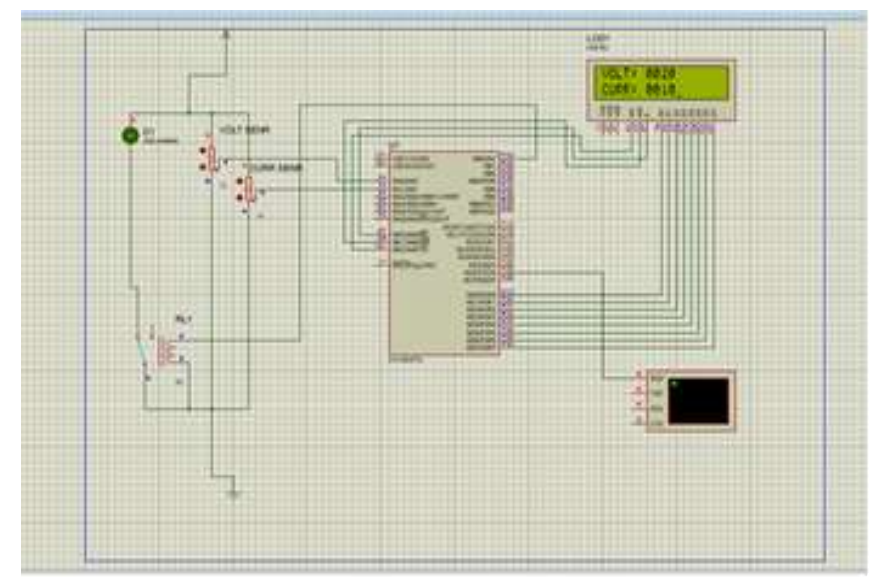

Fig. 3: Voltage $>15 \mathrm{~V}=$ Load connected to the Solar Panel

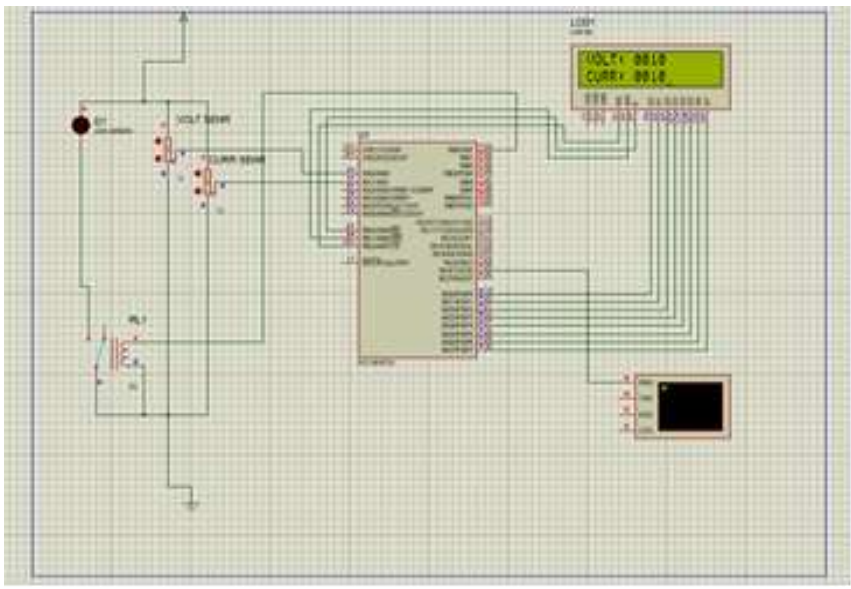

Fig. 4: Voltage $<15 \mathrm{~V}=$ Load connected to the Electricity Grid

\section{HARDWARE DESCRIPTION}

\section{A. Components}

PIC Microcontroller (PIC16F877A)

$>$ Current sensor (ACS712)

$>$ LCD (8 Data Pin)

$>$ Voltage sensor $(0 \mathrm{~V}-25 \mathrm{~V})$

$>$ Relay (2 Switch)

$>$ GSM Module

$>$ Battery $(12 \mathrm{~V})$

$>$ IOT(ESP-12E BASED NODEMCU)

\section{B. Hardware Setup}

The PIC microcontroller is responsible for the control of the circuit. The solar panel is connected to the battery and the battery is connected to the PIC. The voltage sensor, current sensor and relay are also connected to the PIC microcontroller. The voltage and current sensor are responsible for monitoring the available quantities which is compared to a standard minimum voltage and current. The NODEMCU is available as the IOT unit and is responsible for connecting to the server and controlling the smart 


\section{IOT BASED SOLAR POWER MANAGEMENT USING SMART SWITCHING}

switching. The switching is handled by the relay when coded through the PIC. The GSM module is also coded in such a way that it sends message to registered phone number.

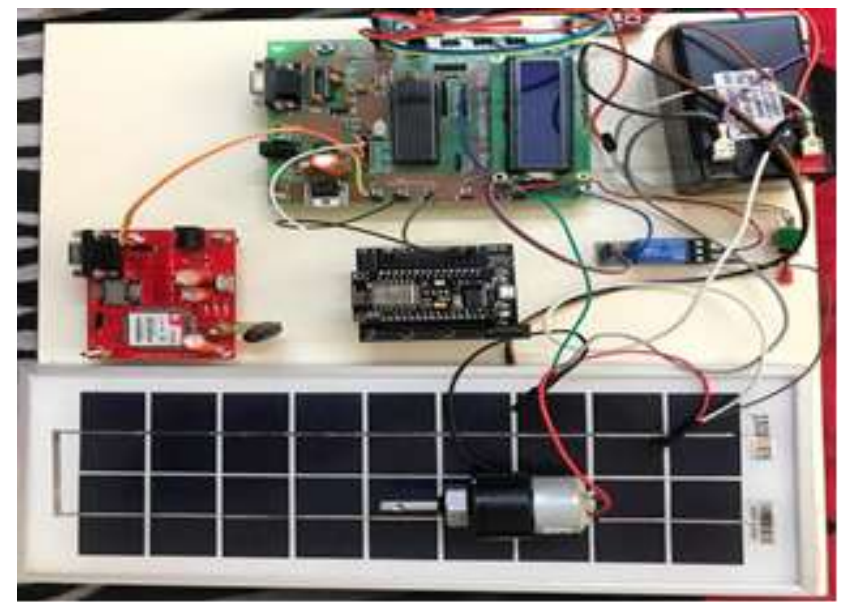

Fig. 5: Hardware Setup

\section{RESULTS}

The monitoring device was realized using the above-mentioned system details and was put to test in the required environment. We were able to receive the sensor data from both the sensors continuously. This helped us to know the exact power continuously at each moment. The GSM module sent messages to the registered number and then the server was accessed and then the load was switched to electricity board as soon as there was low battery. In the IOT control section, when we switch on the 'S1' switch the load is switched to EB and disconnected from the solar panel battery. This is how efficient monitoring and control of a load using a solar panel is established, elimination all the manual labor and errors.

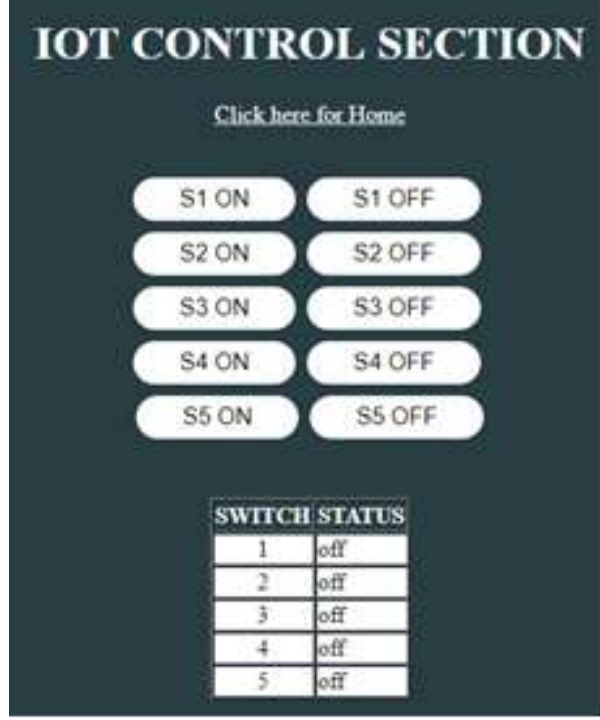

Fig. 6: IoT Control Section.

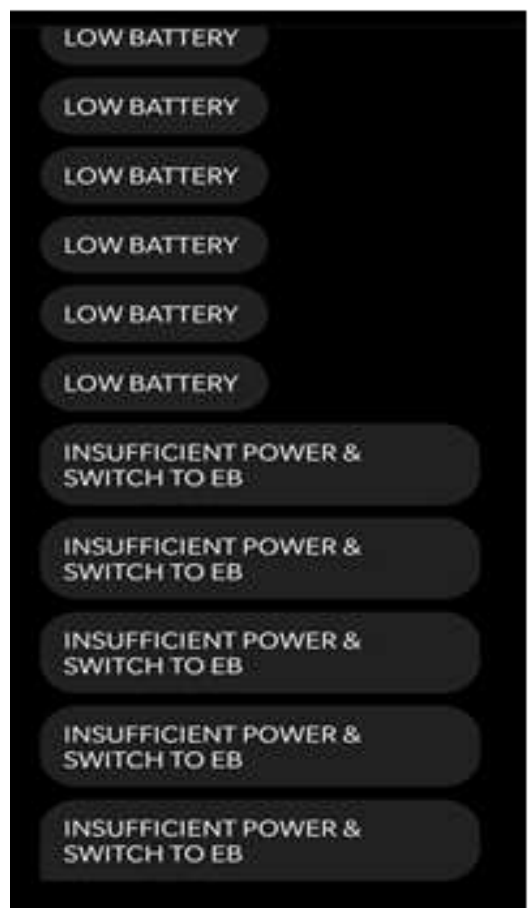

Fig. 7: GSM Module messages

\section{APPLICATIONS}

- Hospitals: If there is a fault in any part of the connection in the hospital, even then we can get uninterrupted monitoring as well as control.

- Farms: The transportation cost of the farmers reduces as they get full control everywhere.

- Nuclear Reactor: As we have seen in 2011, there was failure in one of reactors so the whole power plant was shut down. In those scenarios this self-powered monitoring and controlling will be huge help.

- Home: At personal homes this can give us true power consumption and we can remotely control each and every load.

\section{CONCLUSION}

In today's world, IOT is advancing and we have to advance with IOT. It is high time we leave past the manual errors. Smart Grid innovations are changing the way in which vitality is created and appropriated, empowering utility administrators to all the more precisely gauge use and to source vitality from the most savvy providers. IOT sharp framework applications can likewise empower vitality clients to all the more adequately screen and control their vitality utilization, in this manner diminishing utilization just as the requirement for included framework. 


\section{REFERENCES}

1. S. Mondal and R. Paily, "Efficient Solar Power Management System for Self-Powered IoT Node," IEEE Trans. Circuits Syst. I Regul. Pap., vol. 64, no. 9, pp. 2359-2369, 2017.

2. O. Chieochan, A. Saokaew, and E. Boonchieng, "Internet of things (IOT) for smart solar energy: A case study of the smart farm at Maejo University," 2017 Int. Conf. Control. Autom. Inf. Sci. ICCAIS 2017, vol. 2017-Janua, pp. 262267, 2017.

3. B. Shrihariprasath and V. Rathinasabapathy, "A smart IoT system for monitoring solar PV power conditioning unit," IEEE WCTFTR 2016 - Proc. 2016 World Conf. Futur. Trends Res. Innov. Soc. Welf., 2016.

4. A. S. Spanias, "Solar energy management as an Internet of Things (IoT) application," 2017 8th Int. Conf. Information, Intell. Syst. Appl. IISA 2017, vol. 2018 Janua, pp. 1-4, 2018.

5. M. D. Phung, M. De La Villefromoy, and Q. Ha "Management of solar energy in microgrids using IoT-based dependable control," 2017 20th Int. Conf. Electr. Mach. Syst. ICEMS 2017, 2017.

6. N. Zhang, W. Zhao, J. Lin, W. Yu, H. Zhang, and X. Yang, "A Survey on Internet of Things: Architecture, Enabling Technologies, Security and Privacy, and Applications," IEEE Internet Things J., vol. 4, no. 5, pp. 1125-1142, 2017.

7. R. J. Tom, S. Sankaranarayanan, and J. J. P. C. Rodrigues, "Smart Energy Management and Demand Reduction by Consumers and Utilities in an IoT-Fog based Power Distribution System," IEEE Internet Things J., no. 1, pp. $1-1,2019$.

8. O. For and N. Of, "Dc / Dc C Onverters for G Rid I Ntegration of L Arge -S Cale S Olar," 2017 Int. Conf. Energy, Commun. Data Anal. Soft Comput., pp. 17-19, 2012.

9. G. Kortuem, F. Kawsar, D. Fitton, and V. Sundramoorthy, "Smart objects as building blocks for the internet of things," IEEE Internet Comput., vol. 14, no. 1, pp. 44-51, Jan./Feb. 2010.

10. C. Lu, S. P. Park, V. Raghunathan, and K. Roy, "Low-overhead maximum power point tracking for micro-scale solar energy harvesting systems," in Proc. 25th Int. Conf. VLSI Design, Jan. 2012, pp. 215-220.

11. Y. K. Ramadass and A. P. Chandrakasan, "A battery-less thermoelectric energy harvesting interface circuit with 35 $\mathrm{mV}$ startup voltage," IEEE J. Solid-State Circuits, vol. 46, no. 1, pp. 333-341, Jan. 2011.

12. R. Yao, W. Wang, M. Farrokh-Baroughi, H. Wang, and Y. Qian, "Quality-driven energy-neutralized power and relay selection for smart grid wireless multimedia sensor based IoTs," IEEE Sensors J., vol. 13, no. 10, pp. 3637-3644, Oct. 2013.

13. A. Prijíc, L. Vra car, D. Vu`ckoví c, D. Milíc, and Z. Priji c, "Thermal energy harvesting wireless sensor node in aluminum core PCB technology," IEEE Sensors J., vol. 15, no. 1, pp. 337-345, Jan. 2015

14. C. Park and P. H. Chou, "AmbiMax: Autonomous energy harvesting platform for multi-supply wireless sensor nodes," in Proc. 3rd Annu. IEEE Commun. Soc. Sensor Ad Hoc Commun. Netw. (SECON), vol. 1. Sep. 2006, pp. 168-177.

15. H. Shao, C.-Y. Tsui, and W.-H. Ki, "The design of a micropower management system for applications using photovoltaic cells with the maximum output power control," IEEE Trans. Very Large Scale Integr. (VLSI) Syst., vol. 17, no. 8, pp. 1138-1142, Aug. 2009.

16. Y.-C. Shih and B. P. Otis, "An inductorless DC-DC converter for energy harvesting with a 1.2- $\mu \mathrm{w}$ bandgap-referenced output controller," IEEE Trans. Circuits Syst. II, Exp. Briefs, vol. 58, no. 12, pp. 832-836,
Dec. 2011.

17. K. Ishaque and Z. Salam, "A deterministic particle swarm optimization maximum power point tracker for photovoltaic system under partial shading condition," IEEE Trans. Ind. Electron., vol. 60, no. 8, pp. 3195-3206, Aug. 2013.

18. C. Vankecke et al., "Multisource and battery-free energy harvesting architecture for aeronautics applications," IEEE Trans. Power Electron., vol. 30, no. 6, pp. 32153227, Jun. 2015.

19. S. Bandyopadhyay and A. P. Chandrakasan, "Platform architecture for solar, thermal, and vibration energy combining with MPPT and single inductor," IEEE J. Solid-State Circuits, vol. 47, no. 9, pp. 2199-2215, Sep. 2012.

20. E. J. Carlson, K. Strunz, and B. P. Otis, "A $20 \mathrm{mV}$ input boost converter with efficient digital control for thermoelectric energy harvesting," IEEE J. Solid-State Circuits, vol. 45, no. 4, pp. 741-750, Apr. 2010.

21. S. Mondal and R. P. Paily, "An efficient on chip power management architecture for solar energy harvesting systems," in Proc. 29th Int. Conf. VLSI Design, Jan. 2016 pp. 224-229.

22. P. Nintanavongsa et al., "Design optimization and implementation for RF energy harvesting circuits," IEEE J. Emerg. Sel. Topics Circuits Syst., vol. 2, no. 1, pp. 24 33, Mar. 2012. 